\title{
A EXPANSÃO DOS INVESTIMENTOS EXTERNOS DIRETOS CHINESES. O CASO DO SETOR ENERGÉTICO BRASILEIRO
}

\section{The expansion of Chinese foreign investment: the case of the Brazilian energy sector}

\author{
Giorgio Romano Schutte \\ Victor Sant'Anna Debone ${ }^{2}$
}

\section{Introdução}

A ascensão econômica chinesa foi um dos grandes fenômenos na trajetória do capitalismo global nas últimas duas décadas do século XX. Nessa fase, a internacionalização da economia chinesa se dava prioritariamente pela exportação. A China aumentou sua participação no comércio internacional de uma média de 1,4\%, na década de 1980, para 4,3\%, em 2001, quando formalizou sua entrada na Organização Mundial de Comércio (OMC). E, em 2010, já superava a marca de 10\%, o que provocou uma acumulação extraordinária de reservas internacionais, que aumentaram de um patamar de US\$2,2 bilhões, em 1980, para US\$ 3,2 trilhões, em julho $2016^{3}$.

A abertura de Deng Xiaoping, a partir de 1979, focava na atração dos Investimentos Externos Diretos (IED) com capitais da diáspora chinesa e, em seguida, das empresas transnacionais dos países centrais (ARRIGHI, 2008). A atração dos IED era considerada um elemento crucial para modernizar a

\footnotetext{
${ }^{1}$ Possui mestrado em Relações Internacionais pela Universidade de Amsterdam (1987) e doutorado em Sociologia pela Universidade de São Paulo (2003). Atualmente é Professor Adjunto IV, Coordenador do Curso de Relações Internacionais (BRI) e membro do corpo docente do Programa de pós-graduação em Ciências Humanas e Sociais (PCHS) e do Bacharelado em Ciências Econômicas (BCE) da Universidade Federal do ABC (UFABC). Foi Técnico em Planejamento e Pesquisa e Coordenador da área de estudo de economia e política internacional do IPEA. Atuou como professor em RI do Centro Universitário Belas Artes de São Paulo e consultor senior do Banco Mundial como Regional Advisor na América do Sul da Aliança de Cidades/ Cities Alliance. Ocupou cargos na administração pública federal (Presidência da República) e municipal (Prefeituras de São Paulo e Santo André). Tem experiência na área de Ciências Sociais, com ênfase em Relações Internacionais, atuando principalmente nos seguintes temas: Economia Política Internacional, Geopolítica da Energia, América do Sul, Política Externa Brasileira, Integração e Economia Brasileira Contemporânea. Membro do Grupo de Estudos da Conjuntura da Fundação Perseu Abramo (FPA), do Grupo de Reflexão sobre Relações Internacionais (GR-RI) e do Grupo de Conjuntura Internacional da USP (GACINT). Membro da Associação Brasileira de Relações Internacionais (ABRI). Email: giorgio.romano@ufabc.edu.br

${ }^{2}$ É Bacharel em Relações Internacionais e em Ciências e \& Humanidades pela Universidade Federal do ABC (UFABC). Foi bolsista de Iniciação Científico pelo CNPq no período 08.2015-07.2016 e 06.2016-01.2017 e bolsista Fapesp no período 07.2017-01.2018. Email: debonev@gmail.com

${ }^{3}$ http://www.tradingeconomics.com/china/foreign-exchange-reserves
} 
economia chinesa (ACIOLY, 2005). Outro elemento era um conjunto de políticas econômicas de estímulo para que as empresas chinesas pudessem aproveitar os investimentos das multinacionais dos países do capitalismo avançado e entrar em uma trajetória de incorporação de tecnologias e aumento da produtividade (FLASSBECK, 2005). Nesse período, os IED da China para fora apresentavam volumes irrisórios e as empresas estavam sujeitas a restrições por parte do governo (WOO, ZHANG, 2006)

Foi em 2001 que o vice-premier Wu Bangguo anunciou a política conhecida a partir de então como go global, que seria confirmada como estratégia pelo próprio presidente Wen Jiabao, em 2004, quando declarou, no Congresso Nacional do Povo, que precisava acelerar a implementação desta política e guiar os investimentos para o exterior (WILLIAMSON \& RAMAN, 2011). A partir de então começou um crescimento expressivo dos IED chineses (tabela 1), tornando o país a segunda origem de IED em volume, somente atrás dos Estados Unidos (UNCTAD, 2017).

Gráfico 1 Fluxos de entrada e saída de IED na China 2004-2016 (em bilhões de US\$)

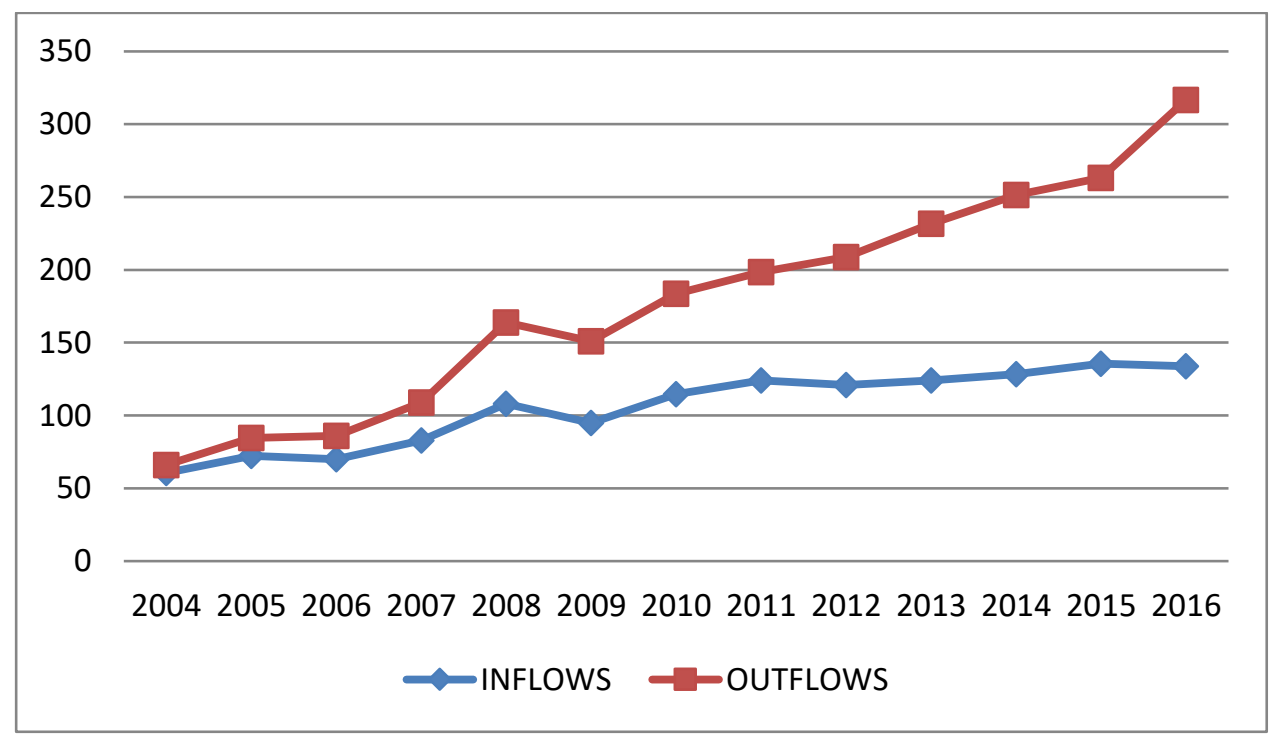

Fonte: Unctad (2017), elaboração própria.

Após a crise global de 2008, e, sobretudo, a partir da ascensão do Xi Jinping à presidência, em 2013, começou a ser delineada uma nova política econômica, conhecida como o New Normal. ${ }^{4}$ É mais comum referir-se ao New Normal somente em termos de busca de um novo modelo de crescimento interno, com maior prioridade para os setores de consumo, em detrimento dos investimentos pesados, caraterística da fase anterior. E com mais ênfase no meio ambiente, no contexto de manutenção do foco no compreensive development, em vez de meramente crescimento econômico. Há, porém, outro pilar dessa nova política, que aponta para a busca de uma inserção internacional mais ativa. Em 2014, considerando a totalidade da conta

\footnotetext{
${ }^{4}$ Durante um discurso no encontro de CEOs na Cúpula de Asean, em 2014, em Beijing, o presidente Xi Jinping detalhou pela primeira vez as características do New Normal para o desenvolvimento da economia chinesa. Disponível em: https://www.youtube.com/watch?v=JOMcwqIC6_E, Acessado 25 de julho de 2016.
} 
de capitais, a China se tornou, pela primeira vez, um exportador líquido de capitais ${ }^{5}$ e, em 2016, o fluxo de IED para fora superou as entradas dos investimentos produtivos, como pode ser observado no gráfico 1 .

Nessa estratégia o Brasil ocupou um papel de destaque. No período entre 2005 e 2016, ficou em quarto lugar entre os países receptores de IED chineses, com US\$ 45,6 bilhões de investimentos acumulados de um total de US\$ 858,2 bilhões, atrás somente dos EUA (US\$ 149,7 bilhões), da Austrália (US\$ 84,6 bilhões) e do Canadá (US\$ 46 bilhões) e à frente do Reino Unido (US\$ 44,7 bilhões), principal porto de entrada na Europa $^{6}$. Houve um destaque para os investimentos nos setores de energia, mais especificamente petróleo e eletricidade, aos quais são dirigidos mais de dois terços do total dos IED chineses no Brasil (CEBC, 2017). O objetivo deste artigo é analisar a dinâmica desses investimentos a partir da estratégia global das empresas estatais no âmbito da busca de uma nova inserção do país na divisão internacional de trabalho.

A fim de realizar esta discussão, o trabalho está organizado em cinco seções, incluindo esta introdução. Na segunda seção, recupera-se a discussão sobre os IED para identificar as referências e analisar a atuação das estatais chinesas. Na terceira seção, foca-se nos investimentos chineses em petróleo no Brasil, a partir de uma análise da dinâmica do setor e seus atores na China. Os investimentos no setor elétrico serão objeto da quarta seção, seguida de considerações finais.

\section{A lógica dos investimentos externos diretos}

Na Economia Política Internacional, há um amplo debate sobre a interação entre Estado e empresas multinacionais. Os Estados são os principais responsáveis pela ordenação do sistema internacional, mas também estão sujeitos às mudanças na ordem econômica global. Segundo Robert Gilpin,

States, particularly large states, establish the rules that individual entrepreneurs and multinational firms must follow, and these rules generally reflect the political and economic interests of dominant states and their citizens. However, economic and technological forces also shape the policies and interests of individual states and the political relations among states, and the market is indeed a potent force in the determination of economic and political affairs. The relationship of economics and politics is interactive (GILPIN, 2001, p. 23).

A expansão global do capitalismo americano no período pós-Segunda Guerra Mundial tinha as empresas multinacionais como um de seus elementos constitutivos. Foi por meio de seus investimentos que se integrou a reconstrução da Europa ocidental ao processo de acumulação estadunidense em um processo que Pijl chamou de "ofensiva Marshall" (PIJL, 2012 p.138). Com outra abordagem, Serven-Schreiber (1967) também havia identificado os investimentos das empresas americanas como parte da dominação política cultural dos EUA sobre a Europa. Esse movimento ganhou uma nova dimensão a partir do final da década de 1970, no processo de reestruturação capitalista. diante das conquistas dos trabalhadores nos países centrais, do avanço das forças autônomas a partir de estados nacionais em países em desenvolvimento e do

\footnotetext{
${ }^{5}$ https://data.worldbank.org/indicator/BN.TRF.KOGT.CD?locations=CN

${ }^{6}$ Dados do China Global Investment Tracker (CGIT) da American Enterprise Institute/ Heritage Foundation. Em números totais há uma relativa convergência com os dados divulgados pelo próprio governo chinês por meio do Ministério de Comércio (Mofcom), mas há diferenças nos dados de destino, porque o CGIT tenta acompanhar os fluxos até seu destino final.
} 
acirramento da concorrência intercapitalista, em particular com a ascensão econômica do Japão e da Alemanha. A partir de meados da década de 1980, consolidou-se a reorganização do capitalismo global liderada pela expansão das finanças, mas também por um crescimento expressivo dos IED (tabela 1). Em termos quantitativos os IED superaram as taxas já expressivas de crescimento do comércio internacional.

Tabela 1 - IED global 1980-2016 em US\$ constantes de 2016

\begin{tabular}{|l|l|}
\hline Período & Média anual em US\$ em preços constantes de 2016 \\
\hline $1980-1985$ & US\$ 141,2 bilhões \\
\hline $1986-1990$ & US\$ 310,2 bilhões \\
\hline $1991-1995$ & US\$ 372 bilhões \\
\hline $1996-2000$ & US\$ 1,15 trilhão \\
\hline $2001-2005$ & US\$ 928,5 bilhões \\
\hline $2006-2010$ & US\$ 1,691,8 trilhão \\
\hline $2011-2016$ & US\$ 1,631,6 trilhão \\
\hline
\end{tabular}

Fonte: UNCTADstat; para a conversão em valores constantes: Bureau of Labor Statistics (https://data.bls.gov/cgi-bin/cpicalc.pl). Elaboração própria.

Entre 1990 e 2016, o PIB Mundial cresceu 77,8\% (de US\$ 42,339 trilhões para US\$ 75,259 trilhões em dólares constantes de 2016), contra um aumento de 156\% das exportações totais, de 372\% no fluxo de IED e de $308,5 \%$ das vendas totais das filiais das multinacionais no mesmo período (ver tabela 2). Esses dados corroboram a tese de uma aceleração do processo de internacionalização puxado pelos IED. Há de se considerar ainda que não estão computados nesses dados os fluxos comerciais a partir de empresas subcontratadas. Nesse mesmo período, o percentual de fusões e aquisições internacionais sobre o total de IED aumentou de $40 \%$ para $60 \%$, indicando o processo de centralização de capital como outra característica desse movimento (UNCTAD, 2017).

Tabelas 2 - Comparação entre exportação global, fluxos de IED e vendas das subsidiárias de multinacionais (em US\$ constantes 2016)

\begin{tabular}{|l|l|l|l|l|l|}
\hline & $\mathbf{1 9 9 0}$ & $\begin{array}{l}\mathbf{2 0 0 5 - 2 0 0 7} \\
\text { Média anual }\end{array}$ & $\mathbf{2 0 1 4}$ & $\mathbf{2 0 1 6}$ & $\begin{array}{l}\text { Variação entre 1990 } \\
\text { e 2016 em \% }\end{array}$ \\
\hline $\begin{array}{l}\text { Exportações } \\
\text { totais mundiais }\end{array}$ & $\begin{array}{l}\text { US\$ 7,983 } \\
\text { trilhões }\end{array}$ & $\begin{array}{l}\text { US\$ 17,888 } \\
\text { trilhões }\end{array}$ & $\begin{array}{l}\text { US\$ 24,224 } \\
\text { trilhões }\end{array}$ & $\begin{array}{l}\text { US\$ 20,437 } \\
\text { trilhões }\end{array}$ & $156 \%$ \\
\hline Fluxo IED global & $\begin{array}{l}\text { US\$ } 370 \\
\text { bilhões }\end{array}$ & $\begin{array}{l}\text { US\$ } 1,7 \\
\text { trilhões }\end{array}$ & $\begin{array}{l}\text { US\$ } \\
\text { trilhão }\end{array}$ & US\$1,75 & $372 \%$ \\
\hline $\begin{array}{l}\text { Vendas totais } \\
\text { das filias de } \\
\text { empresas } \\
\text { multinacionais }\end{array}$ & $\begin{array}{l}\text { US\$ 9,197 } \\
\text { trilhões }\end{array}$ & $\begin{array}{l}\text { US\$ 23,895 } \\
\text { trilhão }\end{array}$ & $\begin{array}{l}\text { US\$ 34,420 } \\
\text { trilhões }\end{array}$ & $\begin{array}{l}\text { US\$ 37,570 } \\
\text { trilhões }\end{array}$ & $308,5 \%$ \\
\hline $\begin{array}{l}\text { Exportações das } \\
\text { filiais de } \\
\text { empresas } \\
\text { multinacionais }\end{array}$ & $\begin{array}{l}\text { US\$ 2,598 } \\
\text { trilhões }\end{array}$ & $\begin{array}{l}\text { US\$ 5,953 } \\
\text { trilhões }\end{array}$ & $\begin{array}{l}\text { US\$ 8,075 } \\
\text { trilhões }\end{array}$ & $\begin{array}{l}\text { US\$ 6,812 } \\
\text { trilhões }\end{array}$ & $162,2 \%$ \\
\hline
\end{tabular}

Fonte: UNCTAD (2017, p. 26); para a conversão em valores constantes: Bureau of Labor Statistics (https://data.bls.gov/cgibin/cpicalc.pl). Elaboração própria. 
Analisando as mudanças quantitativas e qualitativas dos fluxos de IED, Nunnenkamp (1997) falou no surgimento de uma "produção globalizada", com novas formas de organização e uso de novas tecnologias. A utilização da telemática permitiu uma coordenação muito maior das cadeias produtivas (da pesquisa à distribuição) em nível internacional. Esse processo combina uma descentralização da produção com a centralização do controle e apropriação do valor agregado. Panitch e Gindin chamam a atenção para o reforço do papel do capital americano:

[...] the commanding Heights of global accumulation had shifted to these hight-tech sectors, and to a range of business services (management, legal, accounting, engineering, consultancy and financial) in which American corporations overwhelmingly dominated (PANITCH, GINDIN, 2015, p. 37)

Para esses atores, é preciso ainda identificar a centralidade do Estado americano na garantia da infraestrutura monetária e regulatória, como teria sido demonstrado com as operações do US Federal Reserve (FED) diante da crise global de 2008 (idem, p. 41).

A abertura de Deng a partir do início de 1980 encontrou sua contrapartida nessa expansão dos IED globais descrita acima, gerando uma versão chinesa do "desenvolvimento-dependente associado" . $\mathrm{O}$ crescimento da participação chinesa na economia mundial a partir da década de 1980, mas, sobretudo, a partir de 2000, tinha se dado em uma relação complementar à economia norte-americana. A China se tornou a nova fronteira de expansão do capitalismo americano, e as reservas em dólar acumuladas com a capacidade exportadora serviam para o endividamento do hegemon, garantindo, por sua vez, a demanda pelas importações chinesas. A tabela 3 mostra o crescimento expressivo da participação da China como destino dos IED globais, que pulou de próximo a zero até o início da década de 1980 para uma média de 8\% dos IED globais anuais na década de 1990, mantendo, a partir de então, esse patamar.

Tabela 3: Participação da China e de Hong Kong no total FDI inflows e outflows em \% no período de 1980 a 2010

\begin{tabular}{|c|c|c|c|c|}
\hline \multirow[t]{2}{*}{ Périodo } & \multicolumn{2}{|c|}{ Média anual \% China } & \multicolumn{2}{|c|}{ Média anual Hong Kong8 } \\
\hline & Inflows & Outflows & Inflows & Outflows \\
\hline 1980-1990 & $1,7 \%$ & $0,34 \%$ & $2 \%$ & $1,1 \%$ \\
\hline 1991-2000 & $8 \%$ & $1,5 \%$ & $2,5 \%$ & $4,9 \%$ \\
\hline $2001-2010$ & $7,4 \%$ & $2 \%$ & $3,5 \%$ & $3,6 \%$ \\
\hline 2011-2016 & $8,2 \%$ & $8,2 \%$ & $6,7 \%$ & $6 \%$ \\
\hline
\end{tabular}

Fonte: UNCTADstat (http://unctadstat.unctad.org/wds/TableViewer/tableView.aspx)

Mas como tinham insistido os próprios Cardoso e Faletto: “...este tipo de desenvolvimento, ou crescimento econômico é desigual e assimétrico, entre os países e no interior de cada pais". O controle

\footnotetext{
${ }^{7}$ Termo cunhado por Cardoso e Faletto (2004, p. 11) para mostrar que os interesses dos grupos dominantes locais dos países periféricos eram conciliáveis com os interesses da classe dominante internacional.

${ }^{8}$ Hong Kong foi devolvido para a China em 1997, mas com alto grau de autonomia. Tanto antes como depois ela serviu como um elo entra a China e os mercados financeiros globais. Desta forma, grande parte de dados sobre fluxos de investimento e comércio de Hong Kong deve ser entendida como parte da entrada e saída da China.
} 
hierarquizado garante uma apropriação da mais valia de forma concentrada na cadeia global de valor (HART-LANDSBERG\&BURKETT, 2006). O exemplo clássico é a produção global de um iPhone, que quando custava US\$ 300 para consumidor nos EUA deixava somente 1,8\% desse valor para remunerar a produção final na China (PANITCH; GINDIN, 2012, p. 288). Nesse sentido, seria possível falar em uma integração subalterna da China às cadeias globais de valor, por depender da tecnologia, mercados e marcas controlados pelas transnacionais dos países centrais, em particular dos EUA, e ter de operar em dólar. O surgimento e crescimento dos IED chineses devem, portanto, ser entendidos como parte de uma estratégia de desenvolvimento para superar essa relação de dependência.

A partir do final da década de 2000, e, sobretudo com a chegada do Xi Jinping à presidência, começou a se consolidar outro cenário. A crise global de 2008 evidenciou a força relativa que a economia chinesa havia ganhado. A superação da crise dependeria, em grande medida, da capacidade da economia chinesa de manter seu dinamismo. O papel da China na economia mundial não estava somente baseado em sua capacidade produtiva e exportadora. A transformação do G-7 em G-20 significava um reconhecimento do papel daquele país na garantia da governança do sistema econômico internacional. Uma China mais autônoma e assertiva precisaria, e poderia, disputar o controle de tecnologia, marcas e mercados para ela mesma organizar e centralizar cadeias globais de valor, subir na hierarquia da divisão internacional de trabalho e se apropriar de uma parcela maior do valor adicionado. Ou seja, na era Xi Jinping, os fluxos de IED chineses tendem a ganhar importância estratégica no contexto de uma nova visão geoeconômica e geopolítica que pretende gerar outras dinâmicas de acumulação de capital a partir de investimentos e financiamentos chineses que disputam os espaços na economia internacional, comprando ativos voltados para o controle de mercados, tecnologias e marcas, tanto nos países centrais quanto nos emergentes. Qingyun (2014), assessor do Conselho de Estado da China, mencionou, nesse contexto, explicitamente, o uso das reservas internacionais para aumentar os Investimentos Externos Diretos.

O $13^{\circ}$ Plano Quinquenal fala explicitamente em "a new stage in China's opening up" (Central Committe CCP, 2015, p. 141) e specifically afirma: “We will support enterprises in increasing overseas investment and becoming more deeply integrated into global production, value, and logistics chains" (idem, p. 143). E, apesar do crescente papel do setor privado ${ }^{9}$, ou melhor, de empresas não diretamente controladas pelo o Estado, o Plano refirma o papel das estatais:

We will remain firmly committed to ensuring that state-owned enterprises (SOEs) grow stronger, better, and bigger and work to see that a number of such enterprises develop their capacity for innovation and become internationally competitive, thereby injecting greater life into the state-owned sector, helping it exercise a greater level of influence and control over the economy, increasing its resilience against risk, and enabling it to contribute more effectively to accomplishing national strategic objectives (idem, p. 34).

\footnotetext{
${ }^{9}$ Scissors questionou a relevância em enfatizar a diferença entre SOE's e empresas privadas: ““ Genuinely private Chinese entities have no more protection from the CP than SOEs". (SCISSORS, 2017, p. 8)
} 
Dentro da perspectiva que adotamos é questionável concluir que os IED chineses se diferenciam da dinâmica dos IED dos países do capitalismo avançado simplesmente por terem um componente político e estarem vinculados a um projeto de projeção nacional que possa envolver uma disputa pela hegemonia ${ }^{10} . \mathrm{Na}$ abordagem da Economia Política Internacional sempre houve uma atenção para a relação dos estados nacionais e, em particular, o papel do Estado norte-americano em relação às estratégias das empresas multinacionais, embora essa relação seja mais direta no caso da China pela predominância das empresas estatais e o controle político mais direto sobre as privadas. Elas foram cada vez mais estimuladas a competir nos mercados internacionais, lançando mão das estratégias de seus concorrentes dos países capitalistas avançados, sobretudo no que diz respeito à conquista de mercados, recursos tecnológicos e organizacionais. A abertura de capitais das estatais com listagem nas bolsas de valores tem também esse objetivo de submeter estas empresas à busca de eficiência capitalista. De outro lado, não se pode perder de vista que a China continua sendo um país socialista com controle do Estado e do Partido Comunista, não somente no âmbito político, mas também para direcionar e orientar as atividades econômicas. Pijl caracterizou essa realidade como capitalismo de Estado, que se diferencia, sobretudo pela "defence of state sovereignty against the sovereignty of transnational capital championed by the West."(PIJL, 2017, p. 4) ${ }^{11}$. A capacidade de controle e de planejamento econômico do governo, no curto e no longo prazo, é elemento crucial para explicar a capacidade deste país emergente em projetar-se no sistema internacional globalizado.

Nas próximas seções, serão analisados os investimentos no setor energético no Brasil que constituem uma das prioridades desta expansão dos IED chineses globais. Dunning \& Lundan (2008) elaboraram uma tipologia para diferenciar várias estratégias de internacionalização de empresas que se torna também útil para o caso dos investimentos chineses. Resource seeking: que visa garantir o acesso a recursos naturais (comum em setores extrativistas, como o do petróleo); Market seeking: que visa à entrada em novos mercados (comum em setores de bens de consumo, mas também em infraestrutura); Strategic assets: que visa ao controle de ativos estratégicos, buscando o desenvolvimento de competências tecnológicas ou organizacionais. Efficience seeking: que visa à ampliação da eficiência produtiva. No caso do setor petrolífero (seção 3), os IED chineses seguem prioritariamente a lógica da resource seeking, mas, no caso do setor elétrico (seção 4), há claro indício de uma lógica voltada para market-seeking e projeção de liderança tecnológica.

\footnotetext{
${ }^{10}$ Essa conclusão aparece, entre outros, em um levantamento internacional de estudos mais convencionais sobre os IED chineses feito por Berning e Holtbrugge (2012) e também em Santos e Milan (2014)

${ }^{11} \mathrm{Na}$ cabe no âmbito desse trabalho entrar no debate sobre a formação de novas classes sociais a partir das várias etapas do processo de internacionalização da economia chinesa. Fato é que de um lado surgiu uma classe operaria urbana ligada à produção global com potencial para aspirar uma organização social independente da estrutura estatal. E, de outro, houve a formação de uma classe capitalista com relativa autonomia com relação à estrutura estatal, e sobretudo ao Partido Comunista da China (PCC) e que tem na internacionalização uma forma de aumentar esta autonomia.
} 


\section{Segurança energética e a procura de petróleo}

\section{Evolução do setor petrolífero na China}

O boom industrializante conduzido na China na primeira década do século XXI refletiu-se em uma média de crescimento do PIB superior a $10 \%$ ao ano, impulsionando o aumento em sua demanda por energia. Com isso a China se tornou, a partir de 2009, o maior país consumidor de energia primária no mundo (BP, 2016), sendo o carvão a principal fonte, conforme pode ser observado no gráfico 2. A pesar de seu esforço gigantesco de ampliar as fontes não fósseis (nuclear, hidrelétrica, solar e eólica), a dependência das fontes fosseis ainda é enorme (SCHUTTE\&DEBONE, 2016). O $13^{\circ}$ Plano Quinquenal tem como um de suas metas obrigatórias aumentar o consumo de energia não-fóssil de 12\%, em 2015, para 15\%, em 2020 (Central Committee CCP, 2015, p.18).

Gráfico 2 - China: Evolução da matriz energética (1996-2015) Em milhões de toneladas de óleo equivalente.

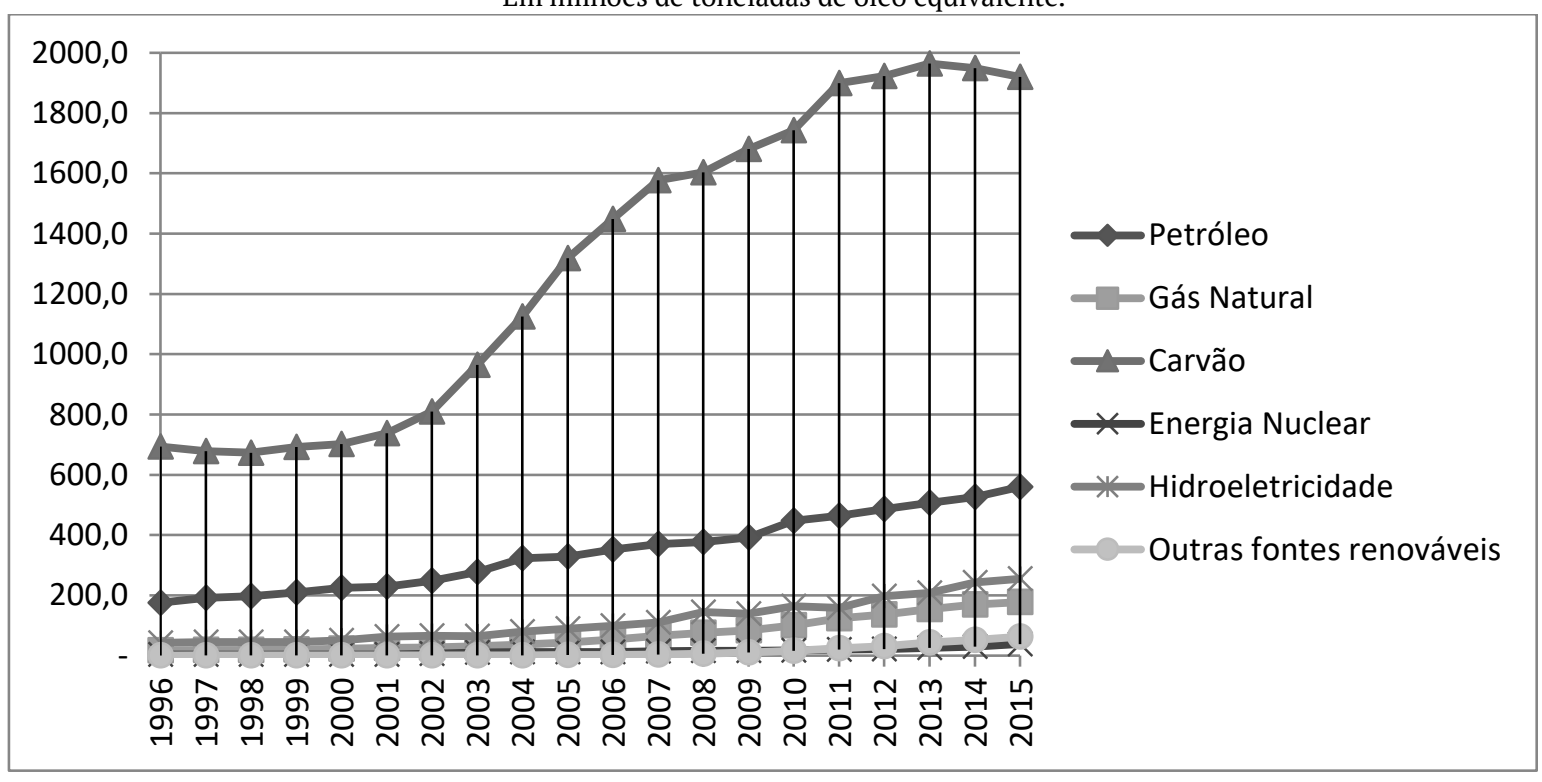

Fonte: BP Statistical Review of World Energy 2016. Elaboração própria.

O carvão, porém, apesar do seu impacto negativo sobre o meio ambiente, tem como vantagem não depender de importações. ${ }^{12}$ A China detém a terceira maior reserva energética comprovada de carvão, atrás apenas dos Estados Unidos e da Rússia (BP, 2016), e é de longe o maior produtor. No caso do petróleo, a situação é muito diferente. Em duas décadas, o consumo de petróleo na China mais que triplicou, de 3,4 mbd (milhões de barris por dia) em 1995, para 12 mbd em 2015 (ver gráfico 3). Enquanto isso, a produção aumentou em um ritmo muito menor, alcançou 4,3 mbd em 2015, consolidando a China como o maior importador de petróleo do mundo. ${ }^{13}$

\footnotetext{
${ }^{12}$ Embora a China tenha passado, em 2009, da tradicional posição de exportador do minério para se tornar o segundo importador líquido de carvão, em 2015 as suas importações eram de 204 Mt contra uma produção local de 3527,2 Mt (IEA, 2016).

${ }^{13}$ Ainda longe da dependência da União Europeia, que registrou, em 2015, um consumo de 12,7 mbd contra uma produção de 1,5 mbd.
} 
Gráfico 3 -China: evolução do consumo e produção de petróleo (2001-2015) Em milhões de barris por dia.

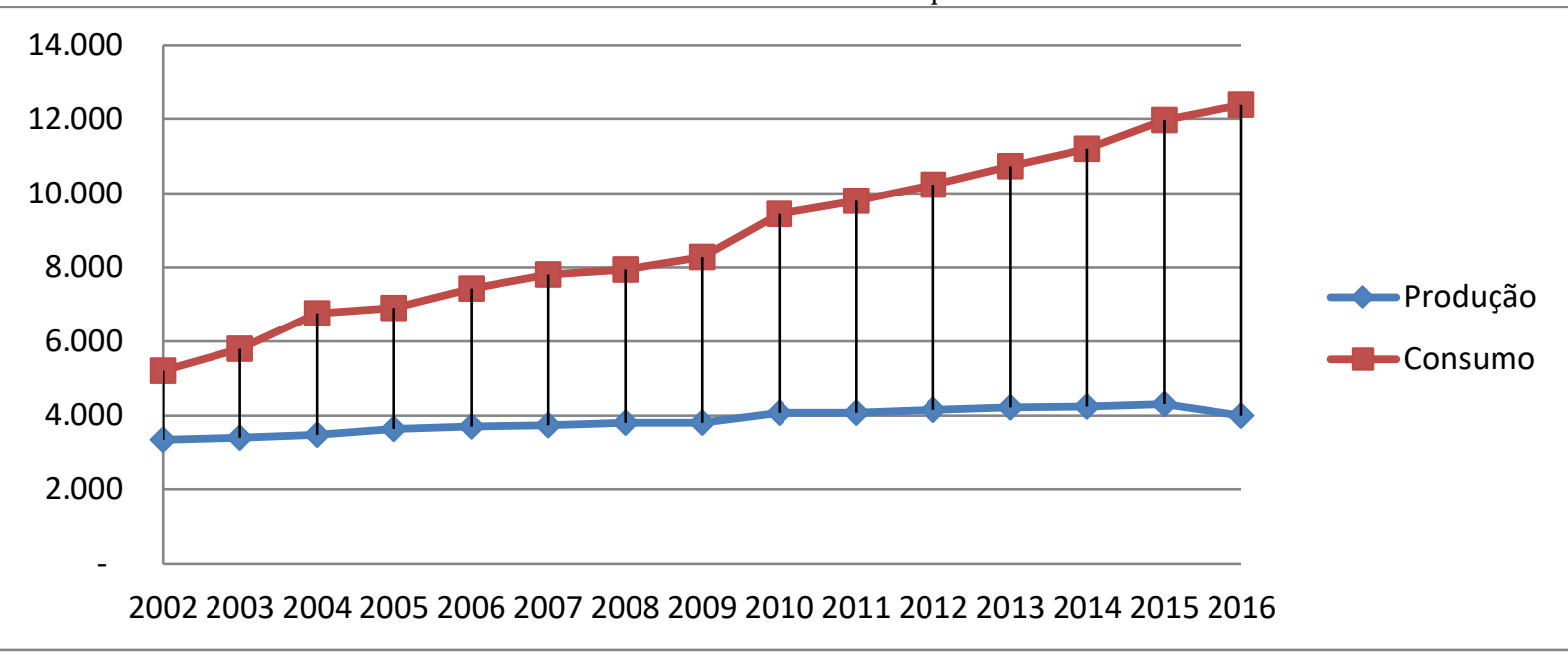

Fonte: BP Statistical Review of World Energy 2015. Elaboração própria

Strange (1987) já havia identificado a energia como fator de maior relevância para a manutenção das estruturas de poder global. O petróleo, embora esteja perdendo sua importância relativa, continua a principal fonte de energia, sendo por excelência motivo de disputa política e militar (FUSER, 2008; NYE, 2011). A Comissão Europeia elaborou, em 2014, o documento "Estratégia europeia de segurança energética”, no qual alerta que: “A segurança energética da UE também tem de ser entendida no contexto de uma crescente procura de energia em âmbito mundial, a qual se espera que aumente 27\% até 2030". Também Yergin (2011) prevê um aumento das vulnerabilidades para garantir a segurança energética, que, de acordo com o autor depende: a) da proteção de ativos, de redes de abastecimento e rotas comerciais e provisões para casos de emergências; b) da capacidade de produzir e adquirir energia, isto é, o acesso físico às fontes; c) das políticas nacionais destinadas a manter o fluxo constante de abastecimento energético; e, o mais importante, d) das políticas em favor da promoção de investimentos e de desenvolvimento das fontes e infraestrutura, o que exige um visão de longo prazo.

Sem dúvida, a crescente demanda por petróleo representa uma das principais ameaças à segurança energética da China. Já em 1998 o governo efetivou uma reestruturação do setor petrolífero, provocando uma integração vertical produtiva e uma concorrência entre as estatais atuantes no setor. Até então, havia uma divisão entre os segmentos na qual cada uma das grandes empresas estatais do país dominava. A CNPC (China National Petroleum Corporation) era responsável pelo upstream (exploração e produção) no ramo onshore (campos de exploração terrestres); a CNOOC (China National Offshore Oil Corporation) cuidava do ramo offshore (plataformas de exploração marítimas); a China Petrochemical Corporation (Sinopec) era a grande empresa do segmento downstream (refino, petroquímica e logística comercial com empresas locais); e a Sinochem Corporation cuidava das importações e exportações e também do setor petroquímico. A distribuição ficava por conta das empresas locais menores. Com a reestruturação, as empresas passaram a se verticalizar para operar em todos os segmentos. Nos anos seguintes, o governo provocou uma abertura de capital com oferta pública inicial (IPO, na sigla inglesa) nas bolsas de valores de Hong Kong, Xangai e Nova 
York. Em todos os casos, o Estado se manteve como controlador e detentor da maioria das ações. ${ }^{14} \mathrm{O}$ objetivo do governo com essa reorganização era preparar as empresas para defender melhor a segurança energética do país sob a palavra de ordem "caminhar sobre duas pernas": uma para desenvolver a indústria doméstica e outra para a expansão internacional (YERGIN, 2011, p. 253).

Assim, sob a orientação do governo, as grandes companhias petrolíferas estatais da China têm se expandido no exterior e, em 2013, já trabalhavam no segmento upstream de 42 países, com destaque para aqueles da região do Oriente Médio, de onde provieram $26 \%$ da produção petrolífera chinesa além-mar em 2013 (EIA, 2015). Estas companhias, com apoio dos bancos chineses, têm comprado ativos para participação em consórcios responsáveis pelo desenvolvimento e produção de hidrocarbonetos em campos estrangeiros de exploração. De acordo com dados do China Global Investment Tracker (AEI, 2016), dos US\$282,41 bilhões em investimentos chineses no setor energético de outros países, entre 2005 e 2015, US\$ 170,61 bilhões $(60,4 \%)$ foram conduzidos pelas quatro grandes companhias petrolíferas: Sinopec, CNPC (PetroChina), CNOOC e Sinochem. Sobretudo após a crise global de 2008, essas empresas vêm fazendo uma série de aquisições, com destaque para a compra pela Sinopec da Addax Petroleum (braço petrolífero do grupo suíço AOG) por US\$ 7,2 bilhões, em 2009, e a incorporação da companhia de petróleo e gás canadense Nexen Inc por US\$15,1 bilhões pela CNOOC, em $2013^{15}$. Após uma série de aquisições menores, a CNOOC se tornou, inclusive, a maior operadora de petróleo no Mar do Norte. ${ }^{16}$

Foi nessa busca para ativos estratégicos que as empresas entraram na exploração em águas ultraprofundas no Brasil, na área conhecida como pré-sal, caracterizada por Yergin (2011) como uma das mais promissoras da nova fronteira da indústria mundial de petróleo.

\section{Atuação das companhias petrolíferas chinesas no Brasil}

A Sinopec está presente no Brasil desde 2004, quando deu início à onda de investimentos chineses no país, liderando a construção do maior trecho do Gasoduto Sudeste Nordeste (Gasene), operado pela Transpetro (subsidiária da Petrobrás). Em outubro de 2010, a Sinopec fechou acordo com a Repsol Brasil para a compra de $40 \%$ de suas ações, pelo montante de US\$ 7,1 bilhões - segunda maior operação já realizada pela Sinopec fora da China, atrás apenas da mencionada aquisição da Addax. Com a ampliação de capital, o nome da subsidiária no Brasil foi atualizado para Repsol Sinopec Brasil, e a entrada de recursos da petroleira chinesa foi anunciada como importante impulso para desenvolver de forma completa os seus ativos brasileiros, especialmente dos campos do bloco BM-S-9 (campos de Lapa e Sapinhoá), localizados na Bacia de Santos, onde possui $25 \%$ de participação. O ano de 2010 foi central para a reformulação da

\footnotetext{
${ }^{14}$ De acordo com os relatórios anuais das empresas, em 2015, o Estado controlava no caso da Sinopec $72 \%$ das ações e no caso da PetroChina $87 \%$.

${ }^{15}$ Cabe aqui lembrar que, em 2005, a CNOOC teve, sob forte pressão política, de desistir da aquisição do controle acionário da petrofilera norteamericana Unicol, embora sua oferta e US\$ 18,5 bilhões era maior que o da concorrente Chevron. http://www.ogj.com/articles/print/volume-103/issue-30/general-interest/cnooc-withdraws-bid-for-unocal-citing-politics.html

16 Daily Mail, 23 ago 2016. Disponível em: <http://www.dailymail.co.uk/news/article-3754249/China-BIGGEST-crude-oil-operatorNorth-Sea-amid-concerns-growing-influence-Britain.html>. Acesso em: $17 \mathrm{dez}$ 2016; CNOOC Limited, Index. Disponível em: <http://www.cnoocltd.com/col/col7321/index.html>. Acesso em: $17 \mathrm{dez} 2016$.
} 
estratégia da Repsol Sinopec Brasil: além da reestruturação de portfólio e aporte de capital da Sinopec, foi a empresa petrolífera estrangeira que mais investiu em exploração no país, evidenciando seu novo foco no segmento upstream. Em novembro de 2011, a Sinopec assinou com a portuguesa Galp Energia um acordo no valor de US\$ 5,18 bilhões para a aquisição de 30\% da subsidiária Petrogal Brasil, em um programa de ampliação de capital da companhia. Conforme acordado, a Sinopec desembolsou US\$ 3,54 bilhões na compra de 30\% dos papéis da Petrogal Brasil e Galp Brasil, sendo de US\$ 1,64 bilhão restante as despesas envolvendo a transação e o pagamento de dívidas que a Petrogal mantinha com a Galp Energia. O negócio permitiu à Sinopec entrar no pré-sal, o que é condizente com os interesses da China em buscar a absorção de expertise na exploração em campos de águas ultraprofundas. Desconsiderando as associações com Repsol e Galp, a Sinopec Corporation tem ainda, sozinha, participação em dois blocos exploratórios da Petrobrás na Bacia do Pará-Maranhão, as quais foram parte resultante do Acordo de Cooperação Estratégica entre a Petrobras, a Sinopec e o China Development Bank (CDB). Dados do ANP (2016) mostram como a Repsol Sinopec se tornou a terceira maior produtora de petróleo e gás no país, detrás da Petrobras e do Grupo Shell/BG. A Sinopec considera o Brasil "um dos projetos-chave para seu crescimento [pois] O pré-sal brasileiro é, sem dúvida, uma das áreas petrolíferas mais promissoras no mundo". ${ }^{17}$

A Sinochem Petróleo, segunda maior chinesa no que diz respeito às operações no Brasil, está presente no país desde maio de 2010, quando anunciou a compra de $40 \%$ do campo de Peregrino, na Bacia de Campos. A companhia chinesa desembolsou US\$3,07 bilhões pela parcela que pertencia à norueguesa Statoil, reduzindo para $60 \%$ a participação desta, que ainda mantém o controle operacional sobre o bloco. Em entrevista à Bloomberg, o presidente da Sinochem Corp. Han Gensheng, comentou: “This transaction will significantly increase Sinochem's interests in the exploration and production business and consolidate our position as one of the leading global players in the oil and chemicals business"18. Dos campos em que a Sinochem atua, Peregrino é o único que, em 2015, já estava na etapa de produção de petróleo, mas a companhia também possui 40\% de participação no campo de Pitangola, na Bacia de Campos, em consórcio formado com a Statoil Brasil (60\%). Em janeiro de 2012, a Sinochem assinou acordo com a anglo-francesa Perenco para a compra de $10 \%$ dos ativos em cinco blocos de exploração do pré-sal, na Bacia do Espírito Santo. ${ }^{19}$

No caso das outras duas estatais chinesas, a CNPC e aa CNOOC, sua atuação no Brasil se deve primordialmente à participação no consórcio vencedor do direito de exploração do campo de Libra no primeiro leilão sob o marco regulatório do pré-sal, realizado em outubro de 2013. O bloco de Libra está localizado em águas ultraprofundas da Bacia de Santos e compreende uma área de cerca de $1.550 \mathrm{~km}^{2} \mathrm{e}$ profundidade de 2.200 metros. O volume total recuperável está estimado entre 8 e 12 bilhões barril de óleo equivalente, BOE, (ANP, 2013). O consórcio vencedor do bloco era formado pela Petrobras (40\%), pela

\footnotetext{
${ }^{17}$ Repsol Sinopec Brasil: Atividades [sem data]. Disponível em: <http://www.repsolsinopec.com.br/web/10157/77>. Acesso em: 17 set 2016.

${ }^{18} \mathrm{http}: / /$ www.theaustralian.com.au/business/chinas-sinochem-takes-36bn-stake-in-brazilian-oilfield/newsstory/47bd886a4d2d36287bd7f4b068e1b0cc

${ }^{19}$ http://www.offshoreenergytoday.com/perenco-farms-out-brazilian-offshore-concessions-to-sinochem/ e China Daily, 09 fev 2012. Disponível em: <http://usa.chinadaily.com.cn/business/2012-02/09/content_14567582.htm>. Acesso em: 14 ago 2016.
} 
anglo-holandesa Royal-Dutch Shell (20\%), pela francesa Total (20\%), e pelas chinesas CNPC (10\%) e CNOOC (10\%). Sendo o primeiro leilão no novo marco regulatório, havia uma preocupação com relação à participação das empresas multinacionais. Por isso, a participação das duas estatais chinesas foi de grande relevância. Foi também a primeira vez que empresas chinesas participaram diretamente de um leilão, uma vez que, até então, sua entrada se dava por meio de compras de participações em blocos já arrematados. A própria CNOOC comentou em seu relatório anual:

In 2015, a successful appraisal was made in the Libra project, which further reinforced the confidence in exploration and appraisal in the block. Brazil is one of the world's most important deepwater oil and gas development regions. The Company will fully leverage on the development opportunities of the Libra project in Brazil to seek a new growth point for production growth (CNOOC, 2015, p. 6).

Uma caraterística importante das estatais do petróleo é a atuação conjunta com os bancos estatais chineses para alcançar os objetivos estabelecidos pelo governo chinês. Exemplo disso foi o acordo envolvendo Sinopec, CDB e a Petrobras. O Acordo de Cooperação Estratégica firmado em 2010 entre a Petrobras e o China Development Bank (CDB) garantiu empréstimo à companhia brasileira no montante de US\$ 10 bilhões, a ser liberado pelo banco no decorrer de dez anos, enquanto a Petrobras se comprometeu com o fornecimento de petróleo à Sinopec - 150 mil barris por dia no primeiro ano de contrato e 200 mil barris por dia nos nove anos seguintes..$^{20}$ Observe-se, portanto, que não é um contrato padrão loan-for-oil, mas um acordo triangular. A Petrobras pagará sua dívida para o CDB em dólar. Em 2016, a Petrobras assinou novo contrato de financiamento com o CDB no valor de US\$ 5 bilhões. E, ao mesmo tempo, assinou também acordos comerciais de fornecimento de petróleo com três companhias chinesas menores - China National United Oil Corporation, ${ }^{21}$ China Zhenhua Oil ${ }^{22}$ e Chemchina Petrochemical ${ }^{23}$. Os três contratos, em conjunto, estabelecem o fornecimento preferencial às empresas de um volume total de 100 mil barris de óleo por dia, por um período de dez anos. ${ }^{24}$ Essa negociação foi resultado do Acordo de Cooperação assinado pela Petrobras e o CDB em 2015, durante visita do primeiro-ministro da China, Li Keqiang. Observe-se que, em 2016, a Petrobras enfrentou mais dificuldades financeiras, com rates baixas e yields altos. Os acordos com a China serviram quase como contraponto ao tratamento dado pelas instituições financeiras ocidentais. Não significa que havia um interesse político, mas muito mais, uma visão de médio e longo prazo visando garantir o suprimento de petróleo que se contrapôs a uma visão de curto prazo guiada pelo comportamento das bolsas de valores. Em setembro 2017, durante visita do presidente Temer a China, foi assinado novo memorando de entendimento para o financiamento de novamente US\$ 5 bilhões igualmente ligado a contratos de fornecimentos com petrolíferas chinesas ${ }^{25}$.

\footnotetext{
${ }^{20}$ Petrobras, 15/04/2010. Disponível em: <http://fatosedados.blogspetrobras.com.br/2010/04/15/>. Acesso em: 13/08/2016.

${ }^{21}$ Subsidiária da CNPC com atividade em comercialização (trading) de petróleo.

${ }^{22}$ Estatal de menor porte, que desde 2003 está envolvida em operações internacionais para garantir o fornecimento de petróleo.

${ }^{23}$ Subsidiária da estatal ChemChina.

${ }^{24}$ Disponível em: <http://www.valor.com.br/empresas/4809595/petrobras-acerta-financiamento-de-us-5-bi-com-china-developmentbank>.

${ }^{25}$ Valor Econômico, 2 de setembro de 2017. http://www.valor.com.br/empresas/5104878/petrobras-faz-acordo-estrategico-com-bancochines Acessado 2 de setembro de 2017.
} 
Outros contratos de financiamento foram assinados entre a Petrobras com o China Export-Import Bank $^{26}$ e o ICBC Leasing. ${ }^{27}$ Nesse caso, a conclusão é que esses bancos operam com uma dupla lógica: de rentabilidade igual à dos bancos ocidentais, mas, de outro lado, aliados às empresas produtivas, em função de objetivos estratégicos alinhados com o governo chinês. Na interpretação da Cintra \& Pinto (2015, p. 1920), trata-se de um transbordamento de capital monetário e bancário para além das fronteiras chinesas, em movimento que, para a China, significa reduzir sua dependência das reservas em títulos do Tesouro americano. Para estes autores, a estratégia financeira chinesa está intimamente ligada à estratégia produtiva e geopolítica da China. E tanto a atuação das petrolíferas quanto a dos bancos confirmaram que o Brasil, a partir das descobertas do pré-sal, é parte da preocupação estratégica de garantir os suprimentos de petróleo. Com isso, se enquadra nos IED da categoria “resource-seeking”, embora haja também um interesse em acompanhar a tecnologia de perfuração em alta-profundidade. A tabela 4 dá um panorama dos principais aquisições das petrolíferas chinesas no Brasil entre 2010 e 2013.

Tabela 4 - Aquisições por parte de petrolíferas chinesas no Brasil 2010-2013

\begin{tabular}{|c|c|c|c|c|}
\hline $\begin{array}{l}\text { Empresa } \\
\text { chinesa }\end{array}$ & Ano & $\begin{array}{ll}\text { Aquisição } & \text { ou } \\
\text { investimento } & \end{array}$ & Valores & Observações \\
\hline Sinochem & 2010 & 40\% Statoil & US\$ 3 bilhões & $\begin{array}{l}\text { Participação campos pré-sal } \\
\text { Peregrino }\end{array}$ \\
\hline Sinopec & 2010 & 40\% Repsol & US\$ 7,1 bilhões & $\begin{array}{l}\text { Mudou nome para Repsol } \\
\text { Sinopec }\end{array}$ \\
\hline Sinopec & 2011 & $\begin{array}{l}\text { 30\% Petrogal } \text { Brasil } \\
\text { (da portuguesa Galp } \\
\text { Energia) }\end{array}$ & US $\$ 5,18$ bilhões & $\begin{array}{l}\text { Campos de Pão de Açúcar e } \\
\text { Sapinhoá no pré-sal }\end{array}$ \\
\hline Sinochem & 2012 & $\begin{array}{l}\text { Compra participações } \\
\text { da ex-OGX em acordo } \\
\text { com Perenco }\end{array}$ & nd & $\begin{array}{l}\text { Cinco blocos na Bacia do } \\
\text { Espirito Santos no pré-sal }\end{array}$ \\
\hline CNPC & 2013 & 10\% Leilão Libra & 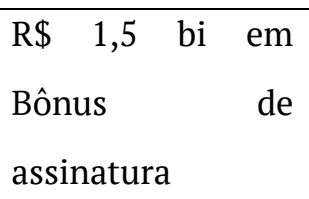 & $\begin{array}{l}\text { Maior campo do pré-sal, } \\
\text { primeiro leilão partilha }\end{array}$ \\
\hline CNOOC & 2013 & 10\% Leilão Libra & $\begin{array}{l}\text { R\$ } 1,5 \text { bi } \\
\text { Bônus } \\
\text { assinatura }\end{array}$ & $\begin{array}{l}\text { Maior campo do pré-sal } \\
\text { primeiro leilão partilha }\end{array}$ \\
\hline
\end{tabular}

Fontes: CEBC; CGIT; Valor Econômico.

\footnotetext{
${ }^{26}$ Petrobras, 09/05/2016. Disponível em: <http://www.petrobras.com.br/fatos-e-dados/financiamento-com-o-china-exim-bank.htm>. Acesso em: 15/08/2016.

27 Petrobras, 13 out 2015. Disponível em: <http://www.petrobras.com.br/fatos-e-dados/contrato-de-financiamento-com-o-icbcleasing.htm>e <http://www.icbcleasing.com/node/100>. Acesso em: 15 ago 2016.
} 


\section{Os gigantes do setor elétrico e sua internacionalização}

\section{Evolução do setor elétrico na China}

O setor elétrico chinês, desde 2011 o maior do mundo em produção TWh, passou por várias reformas desde 1985. Li, Ma e Jorgensen (2016) identificam três fases. Na primeira, de 1985 até 1997, houve um esforço para superar os problemas crônicos de fornecimento que tinham sido identificados como obstáculos para o crescimento. Nesse processo, houve a transformação do monopólio total em um monopólio relativo do Estado. Atingido esse objetivo, iniciou-se a segunda fase, de 1997 a 2002, quando houve um esforço de aumentar a eficiência e a inovação tecnológica. Ocorreu uma clara separação entre as empresas e estrutura do Executivo com a dissolução do Ministério de Indústria elétrica e a transferências de seus ativos para a nova estatal State Power Corporation (SPC), que nasceu com um controle de toda a rede de transmissão e $40 \%$ da capacidade de geração. A reforma de 2002 quebrou a SPC e deu origem a cinco empresas estatais para a geração, com destaque para a China Power Investment Group, e duas para a transmissão, sendo a principal a State Grid. Observe-se, porém, que apesar da descentralização, todas estas empresas ficaram sob o controle direto da State-owned Assets Supervision and Administration Comission (SASEC), ligada ao Conselho do Estado, ou seja, o governo central. A desverticalização, separando geração da transmissão e distribuição, seguia uma tendência internacional do setor (WANG \& CHEN, 2012). No caso da transmissão, o governo optou por grandes investimentos para a ampliação e a integração da rede diante da realidade de termoelétricas a carvão concentradas no norte do país e as hidrelétricas no sudoeste, ou seja, ambas longe dos centros de consumo. Foi também em 2002 que a construtora Three Gorges Corporation, responsável pela construção da maior hidrelétrico do mundo no Rio Yangtze, começou a administrar a geração destas usinas por meio da subsidiária China Yangtze Power. Controladora de outras cinco grandes hidrelétricas, além da Three Gorges, a China Three Gorges (CTG) tornou-se a maior produtora de energia hidrelétrica do mundo, com capacidade instalada de aproximadamente $100 \mathrm{GW}$, tanto já em operação como em construção ${ }^{28}$. Com isso, a China conseguiu expandir sua capacidade instalada de produção elétrica, superando, em 2011, os EUA (ver tabela 5).

Tabela 5 - Evolução anual da produção de eletricidade: China, EUA e o mundo em TWh

\begin{tabular}{|l|l|l|l|}
\hline & $\mathbf{2 0 0 2}$ & $\mathbf{2 0 1 1}$ & $\mathbf{2 0 1 5}$ \\
\hline China & 1,7 & 4,7 & 5,7 \\
\hline EUA & 4 & 4,4 & 4,3 \\
\hline Mundo & 16,2 & 22,2 & 24 \\
\hline
\end{tabular}

Fonte: Global Energy Statistical Yearbook, Enerdata, 2016

\footnotetext{
${ }^{28} \mathrm{http}: / /$ ctgbr.com.br/a-empresa/
} 
A State Grid, que se tornou a maior companhia do mundo em transmissão e distribuição de energia, com receita de US\$ 339 bilhões em 2015, lucro de US\$ 10 bilhões e em torno de 1,9 milhão de funcionários. ${ }^{29}$ Como mencionado, ela foi fundada em 2002 como resultado da aglutinação de capacidades técnicas em diversos segmentos do setor e da crescente capacidade chinesa em pesquisa e desenvolvimento (P\&D). Desta forma, na China ela opera como um “quase monopólio" no desenvolvimento e operação das redes de ultra alta tensão (ultra-high voltage, UHV) em âmbito doméstico. Ela atua de acordo com o planejamento estatal para lograr a construção de um sistema nacional unificado com menor perda possível na transmissão. ${ }^{30}$ A partir da década de 2010, houve um aumento do esforço em inovação tecnológica, especialmente nas áreas de renováveis e fontes alternativas de um lado e, de outro, a otimização da geração e transmissão por meio de investimentos de pesquisa como o State Grid Smart Grid Research Institute em colaboração com universidades de excelência (LI, MA e JORGENSEN, 2016).

O Paulson Institute (2015) analisou os esforços da China em favor da internacionalização da tecnologia de transmissão em linhas de UHV, tendo em vista que a China é o único país onde, desde 2010, se desenvolveu esta tecnologia em larga escala. O estudo concluiu que, "State Grid can use its market power to influence international standardization and allow Chinese companies to include national preferences in international UHV standards" (2015, p. 2). Foi durante o $12^{\circ}$ Plano Quinquenal (2011-2015) que, nas palavras da própria empresa, ela fez o catch-up tecnológico que culminou em liderança tecnológica (SGCC, 2015, p. 29). A chave foi os investimentos em $P \& D$ que resultaram em patentes e padrões de produção industrial. Com isso, apesar de ter iniciado o desenvolvimento das linhas UHV somente em 2008, a China avançou muito mais rápido que países que iniciaram pesquisas e projetos-pilotos nesta tecnologia durante a década de 1960, entre as quais os Estados Unidos. Assim, a State Grid logo se projetou como referência global em tecnologia UHV e já começou a ampliar sua presença internacional. A SGCC atua internacionalmente por meio da subsidiária State Grid International Development Limited (SGID). Segundo a agência de classificação de risco de crédito, Moody’s ${ }^{31}$, ao fim de 2015, a total dos ativos da SGID já tinha alcançado US\$ 16 bilhões, sendo que suas operações no Brasil constituíam cerca de 16\% deste valor.

Há de se destacar o papel crucial da internacionalização de padrões tecnológicos. Nas palavras da OCDE (2016, p. 45)

\footnotetext{
Standardisation work is increasingly conducted internationally, since, in a globalised economy, compatibility and interface across borders are increasingly important. Firms that play primary roles in setting international standards gain advantages from doing so, to the extent that the new standards align with their own standards and/or features of their productive base.
}

\footnotetext{
${ }^{29}$ Disponível em: <http://fortune.com/global500/2015/state-grid-7/ e http://www.sgcc.com.cn/ywlm/aboutus/profile.shtml>. SGBH (2017).

${ }^{30} \mathrm{~A}$ companha afirma, porém, que a implementação de uma ampla rede de linhas UHV transcende esta vantagem de redução das perdas. Ela deve permitir também uma redução dos sistemas de transporte viário e ferroviário de carvão ao ligar as termelétricas no Noroeste do país com os centros consumidores de energia no Leste e facilitar a incorporação da energia renovável na rede.

31 Moody's, 08 jul 2016. Disponível em: <https://www.moodys.com/research/Moodys-State-Grid-International-Developmentsoverseas-investments-have-no-immediate--PR_351793>. Acesso em: 11 set 2016.
} 
E, no caso da tecnologia UHV, esse padrões ainda estão em aberto. State Grid pretende exatamente definir esses padrões, que permitiriam harmonização operacional e, logo eliminar barreiras técnicas. ${ }^{32}$ Não deve causar surpresa que a internacionalização da State Grid, igual a movimentos parecidos em outros setores sensíveis, enfrenta considerável resistência política em razão dos riscos que são atribuídos pela segurança nacional de cada país: o de deixar um serviço fundamental como o abastecimento elétrico a cargo de uma empresa controlada diretamente por outro Estado. Exemplo disso foi a reação do governo australiano diante da vertiginosa expansão da State Grid no setor elétrico do seu país. Em agosto de 2016, ele barrou ofertas de empresas estrangeiras para compra de parcela majoritária da companhia estatal Ausgrid, alegando que a operação iria contra o interesse nacional. A State Grid havia oferecido valor superior a US\$ 7,6 bilhões, por 50,4\% dos ativos da Ausgrid. ${ }^{33}$ Não obstante esses riscos, a promessa de eficiência energética para transmissões a longa distância soa bastante vantajosa para países onde as fontes de energia são localizadas distantes dos grandes centros consumidores (comum no caso de usinas hidrelétricas e fazendas eólicas e solares no Brasil).

Outros players do setor elétrico chinês também seguiram a política de "go-global" após terem adquirido escala e competência tecnológica no mercado interno. A TGC, por exemplo, incorporou a China International Water and Electric Corporation (CWE) para realizar de projetos de construção de novas hidrelétricas, inclusive com apoio do China Exim Bank. Em dezembro de 2011, ela aproveitou o programa de privatização do governo português no âmbito das condicionalidades do pacote de resgate da União Europeia e do FMI, para adquirir 21,35\% do capital da estatal Energias de Portugal (EDP) por 2,69 bilhões de euros, sua maior aquisição até então.

\section{Atuação das elétricas chinesas no Brasil}

Em 2010, o Brasil foi escolhido pela State Grid para a realização do primeiro grande investimento do conglomerado em países não asiáticos (SGBH, 2017). Ela repetiu sua estratégia de realizar movimento duplo de firmar parcerias como forma de ganhar experiência e aquisição de ativos de grandes companhias garantindo fatias expressivas do mercado. A State Grid Brazil Holding (SGBH) investiu, em dezembro daquele ano, US\$ 989 milhões na compra do controle de sete das doze empresas de transmissão subsidiárias da companhia Plena Transmissoras.34 Em março de 2012, a SGBH conquistou a licitação para construir dois trechos do linhão da hidrelétrica de Teles Pires, e firmou parceria com Furnas - Centrais Elétricas S.A. para liderar a construção de duas subestações. Em maio do mesmo ano, a estatal chinesa pagou R \$1,86 bilhão

\footnotetext{
${ }^{32}$ De acordo com o padrão internacional, a transmissão de alta voltagem (HV) abrange de 35 a $22 \mathrm{~kW}$, enquanto a extra-alta voltagem (EHV) atinge o intervalo de 330 a $750 \mathrm{kV}$. Para mérito de comparação, a maioria das linhas de transmissão de longo alcance nos Estados Unidos operam entre $230 \mathrm{~kW}$ e $400 \mathrm{~kW}$. Fonte: Reuters, 19 jun 2014. Disponível em: <http://www.reuters.com/article/uschina-electricity-grid-kemp-idUSKBNOEU19B20140619>. Acesso em: 11 set 2016.

${ }_{33}$ Bloomberg Markets, 19 ago 2016. Disponível em: <https://www.bloomberg.com/news/articles/2016-08-19/australia-bars-foreigninvestors-from-buying-50-4-of-ausgrid-is1gmaue>. Acesso em: $19 \mathrm{dez} 2016$.

${ }^{34}$ A State Grid adquiriu 75\% do capital da Expansión Transmissão de Energia Elétrica e 75\% da Expansión Transmissão Itumbiara Marimbondo; os 25\% restantes permaneceram com a espanhola Abengoa. Fonte: O Globo, 18 jun 2010. Disponível em: <http://oglobo.globo.com/economia/estatal-da-china-compra-controle-de-sete-empresas-de-energia-no-brasil-diz-valor3007244\#ixzz4VV9zN0ZA>. Acesso em: 19 dez 2016.
} 
pelos ativos de sete linhas de transmissão no Brasil, as quais totalizam 2.800 quilômetros e pertenciam ao grupo espanhol Actividades de Construccion y Servicios (ACS)35. Dados oficiais da companhia mostram que, no final de 2012, a State Grid Brazil Holding já era a quinta maior empresa de transmissão no Brasil.36 Em 2014, o consórcio IE Belo Monte - liderado pela SGBH (51\% de participação) em parceria com duas companhias brasileiras subsidiárias da Eletrobras - Eletronorte (24,5\%) e Furnas (24,5\%) - foi o vencedor do leilão da linha de transmissão de Belo Monte. Com investimento previsto em R\$ 5 bilhões, o consórcio se responsabilizou pela construção e operação da Linha de Transmissão Xingu-Estreito, de 2.092 quilômetros e capacidade de $\pm 800 \mathrm{~kW}$, e duas estações conversoras de energia, em projeto de escoamento de energia do Pará aos centros de carga na região Sudeste do país.37 Será o primeiro projeto no país com a tecnologia UHV e há grande expectativa com relação à redução de perdas que poderá ser alcançada. Em seguida, a SGBH venceu também o leilão para a segunda linha de transmissão de Belo Monte para a região Sudeste, cujas obras preveem investimentos em torno de $\mathrm{R} \$ 7$ bilhões, destinados à construção de $2.550 \mathrm{~km}$ de linhas de transmissão de 800 kW e duas subestações. A previsão para o término das obras é janeiro de 2019, com entrada em operação em janeiro de 2020.38

Em 2016, a companhia aproveitou as dificuldades pelas quais a Camargo Corrêa estava passando e adquiriu sua participação na CPFL Energia, o maior grupo privado de geração e distribuição no Brasil, por um valor de R \$ 5,85 bilhões. A SGBH acabou ficando também com as ações do Previ, Petros, entre outros menores, ficando com o 54,64\% do capital social com um investimento total de R\$14,19 bilhões.39 No final de 2016 controlava 18 companhias com 100\% de participação societária e 5 com mais de 51\% (SGBH, 2017).

A estratégia da SGBH corresponde a objetivos globais. Além de representar oportunidade para desenvolver pesquisa, planejamento e técnicas em design e construção, em meio ambiente diferente, os projetos de linhas UHV no Brasil, se bem-sucedidos, reforçarão a confiança mútua na relação sino-brasileira (PAULSON INSTITUTE, 2015, p. 24). Sobretudo, conforme a própria empresa, o sucesso com as linhas de transmissão de Belo Monte servirá como exemplo da competência operacional e tecnológica chinesa (SGCC, 2015, p. 46). E isso deve contribuir com a estratégia de liderar a padronização das linhas de transmissão UHV. No caso da aquisição do controle majoritário da CPFL Energia, a maior empresa privada do setor elétrico brasileiro, esta segue a lógica de aquisições de ativos de grandes empresas do setor elétrico já realizadas nas Filipinas, em Portugal, na Austrália e na Itália: a propriedade sobre estes ativos estratégicos em variados países corresponde a uma estratégia de prazo mais longo de afirmação internacional da

35 O Globo, 10 nov 2012. Disponível em: <http://oglobo.globo.com/economia/gigante-chinesa-escolhe-brasil-como-destino-deinvestimentos-6694778\#ixzz4KRH6ZwDk>. Acesso em: 17 set 2016.

${ }^{36}$ Final de 2012 ela possuía 5,785 Km de linhas de transmissão, 12,803 MW de capacidade de transformação, e 14 subestações. State Grid Brazil Holding (sem data). Disponível em: <http://www.stategridbr.com/about-us.html>. Acesso em: 17 set 2016.

${ }^{37}$ State Grid Brazil Holding, 07 fev 2014. Disponível em: <http://www.stategridbr.com/highlights/belo_monte.html>. Acesso em: 17 set 2016.

${ }^{38}$ State Grid Brazil Holding (sem data). Disponível em: <http://www.stategridbr.com/highlights/belo-monteII.html>. Acesso em 17 dez 2016.

39 Valor Econômico, 15 ago 2016. Disponível em: <http://www.valor.com.br/empresas/4671985/fundos-vao-decidir-pela-venda-desuas-acoes-na-cpfl-para-state-grid>. Acesso em: 18 dez 2016; idem, 23 set 2016. Disponível em: <http://www.valor.com.br/empresas/4723313/previ-adere-proposta-da-state-grid-e-vende-acoes-na-cpfl-energia>. Acesso em: 18 dez 2016; idem, 28 set 2016. Disponível em: <http://www.valor.com.br/empresas/4728105/fundo-energia-sp-aprova-venda-de-fatiada-cpfl-state-grid >. Acesso em: $18 \mathrm{dez} 2016$. 
companhia, que pretende, por meio de controle ou participação em subsidiárias estrangeira, implementar novos projetos de infraestrutura. É nesse contexto que a State Grid e a China estão apostando no sucesso de sua expansão no Brasil, pois este é mais um passo rumo à liderança do gigante asiático em um mercado global que tende a crescer e cujo domínio ainda está em disputa aberta.

A atuação da State Grid tem algo em comum com a das estatais do petróleo e a dos atores estatais que correspondem diretamente ao poder central do governo chinês e que atuam no Brasil como parte de uma estratégia global de longo prazo. Mas, no caso da SGBH, os investimentos não são de tipo resourceseeking. Porém, seguindo a classificação do Dunning \& Ludan, correspondem a uma mistura de market e strategic assets seeking, buscando a liderança mundial.

Seguindo os passos da State Gride, também a CTG escolheu o Brasil como prioritário em sua estratégia de crescimento internacional. Desde que chegou ao país, em 2013, por meio de uma parceria com a Energias do Brasil, realizou alianças estratégicas com empresas reconhecidas no setor. Assim, em 2014, a empresa adquiriu 50\% de participação da hidrelétrica de Santo Antônio do Jari (PA), 50\% da hidrelétrica de Cachoeira Caldeirão (AP) e 33,3\% da hidrelétrica de São Manoel (MT). Em 2015, a CTG adquiriu da Triunfo Participações 100\% das usinas de Salto (GO) e de Garibaldi (SC). Com a concessão adquirida no leilão do Ministério de Minas e Energia, das usinas Jupiá (SP) e Ilha Solteira (SP), assinada em janeiro de 2016, passou a ser a maior geradora de energia do país, após a Eletrobrás. Em dezembro de 2016, o Grupo CTG concluiu a aquisição dos ativos da Duke Energy no Brasil, por um valor de US\$ 946,7 milhões ${ }^{40}$. No início de 2017, ela participava de 17 hidrelétricas e 11 parques eólicos, com uma capacidade instalada de 9,27 GW que estão sob sua gestão ${ }^{41}$. O processo de internacionalização do CTG, do qual o Brasil tornou-se uma peça importante, reflete o esgotamento de oportunidades na própria China. Bi Yaxiong, um alto dirigente da empresa, comentou em entrevista a esse respeito:

Once the downstream Jinsha river (Upper Yangtze) project is completed in 2020, we face the serious situation of having no large-scale hydropower plants left to build, and we won't be able to take full advantage of our core expertise 42 .

Por último, cabe mencionar a oferta vinculante, no final de 2016, do State Power Investment Corporation (SPIC) para comprar a hidrelétrica de Santo Antônio, no Rio Madeira (RO), por R\$ 8 bilhões, e o compromisso de assumir as dívidas líquidas no valor de R\$ 15 bilhões ${ }^{43}$. A SPIC, uma das cinco maiores geradoras de energia elétrica da China, com presença em 35 países, sobretudo da Ásia e África, é fruto de uma fusão realizada em 2015 entre a China Power Investment Corportation e a State Nuclear Power Tecnology Corporation. Esta última tinha aberto, em 2013, um escritório de representação no Rio de Janeiro, visando ao mercado de tecnologia nuclear no Brasil. Essa entrada rápida e em grande escala das estatais CTG e SPIC

\footnotetext{
${ }^{40}$ Valor Econômico, 29/12/2016.

${ }^{41} \mathrm{http}: / /$ ctgbr.com.br/a-empresa

${ }^{42} \mathrm{https} / / /$ www.internationalrivers.org/campaigns/china-three-gorges-corporation Acessado 20 de março de 2017.

${ }^{43}$ Valor Econômico, B2, 12 de abril de 2017. A Usina é controlada por um consórcio composto por Furnas (39\%), Amazônia Energia (20\%), Odebrecht Energia (18,6\%), Andrade Gutierrez (12,4\%), Cemig (10\%).
} 
reflete não só a busca de oportunidades de mercados fora do país, mas também a oportunidade gerada pela crise econômica e financeira das empresas brasileiras do setor.

Tabela 6 - Principais aquisições de ativos no setor elétrico no Brasil por parte de empresas chinesas 2010- 2017

\begin{tabular}{|c|c|c|c|c|}
\hline $\begin{array}{l}\text { Empresa } \\
\text { chinesa }\end{array}$ & Ano & $\begin{array}{l}\text { Aquisição ou } \\
\text { investimento }\end{array}$ & Valores & Observações \\
\hline StateGrid & 2010 & $\begin{array}{llll}\text { Compra de } & 7 & \text { das } & 12 \\
\text { empresas } & & & \text { Plena } \\
\text { Transmissoras } & & \\
\text { (espanhola Elecnor) }\end{array}$ & US\$ 1,7 bilhões & Linhas de transmissão \\
\hline StateGrid & 2012 & $\begin{array}{l}5 \text { empresas de } \\
\text { transmissão de Plena } \\
\text { Transmissoras do grupo } \\
\text { espanhol Abengoa }\end{array}$ & US\$ 989 milhões & \\
\hline StateGrid & 2012 & $\begin{array}{l}\text { 51\% consórcio Matrinchã } \\
\text {-linha de transmissão } \\
\text { Teles Pires }\end{array}$ & & $\begin{array}{l}\text { Linhas de transmissão de cerca } \\
1005 \mathrm{~km}\end{array}$ \\
\hline StateGrid & 2012 & $\begin{array}{l}\text { Compra de } 7 \text { linhas de } \\
\text { transmissão } \\
\text { espanhola ACS }\end{array}$ & R\$ 1,86 bilhão & \\
\hline $\begin{array}{l}\text { China Three } \\
\text { Gorges (CTG) }\end{array}$ & 2014 & $\begin{array}{l}\text { 50\% hidrelétrica Santo } \\
\text { Antônio do Jari (PA) }\end{array}$ & & \\
\hline CTG & 2014 & $\begin{array}{l}50 \% \text { hidrelétrica } \\
\text { Cachoeira Caldeirão (AP) }\end{array}$ & & \\
\hline CTG & 2014 & $\begin{array}{l}\text { 33,3\% hidrelétrica São } \\
\text { Manoel (MT) }\end{array}$ & & \\
\hline StateGrid & 2014 & $\begin{array}{l}\text { 51\% consórcio IE } \text { Belo } \\
\text { Monte- linhão } \\
\text { Monte }\end{array}$ & & $\begin{array}{l}\text { Cerca de } 2092 \mathrm{~km} \text { de Xingu } \\
\text { (PA)-Estreito (MG) }\end{array}$ \\
\hline StateGrid & 2015 & $\begin{array}{l}2^{a} \text { linha de transmissão } \\
\text { Belo Monte }\end{array}$ & $\begin{array}{l}\text { Previsão de } \\
\text { investimentos R\$ } 7 \\
\text { bilhões }\end{array}$ & $\begin{array}{l}\text { Cerca de } 2550 \mathrm{~km} \text { de Xingu } \\
(\mathrm{PA})-\text { Nova Iguaçu (RJ) }\end{array}$ \\
\hline CTG & 2015 & $\begin{array}{l}\text { Compra das } \text { usinas de } \\
\text { Salto (GO) e } \text { Garibaldi } \\
\text { (SC) de } \\
\text { Participações }\end{array}$ & $\mathrm{R} \$ 1,9$ bilhões & \\
\hline CTG & 2015 & 49\% na EDP renováveis & & 11 parques eólicos \\
\hline State Grid & 2016 & $\begin{array}{l}\text { Compra participação } \\
\text { Camargo Corrêa e dos } \\
\text { fundos de pensão (Previ, }\end{array}$ & R\$ 14,19 bilhões & $\begin{array}{l}\text { Entre outros ativos: oito usinas } \\
\text { hidrelétricas Rio Paranapanema }\end{array}$ \\
\hline
\end{tabular}




\begin{tabular}{|l|l|l|l|l|}
\hline & & $\begin{array}{l}\text { Petros, entre outros) na } \\
\text { CPFL Energia }\end{array}$ & & \\
\hline State Gird & 2016 & $\begin{array}{l}\text { Compra CPFL Renováveis } \\
\text { do Camargo Correia }\end{array}$ & R\$ 3,17 bilhões \\
\hline CTG & 2016 & $\begin{array}{l}\text { Jupiá (SP) e Ilha Solteira } \\
\text { (SP), que pertenciam à } \\
\text { CESP }\end{array}$ & $\begin{array}{l}\text { Rônus de outorga } 13,8 \text { bilhões em } \\
\text { boncessão hidrelétricas }\end{array}$ & $\begin{array}{l}\text { Anuncio de R \$ 2,5 a 3 bilhões } \\
\text { de investimentos } \\
\text { modernização até 2026 }\end{array}$ \\
\hline CTG & 2016 & $\begin{array}{l}\text { Compra ativos Duke } \\
\text { Energy Brasil }\end{array}$ & $\begin{array}{l}\text { US\$ 1,2 bilhões } \\
\text { Antônio }\end{array}$ & $\begin{array}{l}\text { Alteração do nome para CTG } \\
\text { Paranapanema }\end{array}$ \\
\hline SPIC & 2017 & $\begin{array}{l}\text { Compromisso de assumir a } \\
\text { dívida de R\$ 15 bilhões }\end{array}$ \\
\hline
\end{tabular}

Fontes: CEBC; CGIT; Valor Econômico.

\section{Considerações Finais}

Tudo indica que o início da década de 2010 marcou uma nova fase da inserção chinesa na economia internacional. Conhecido por sua força exportadora de produtos manufaturados, o país se tornou uma das maiores fontes de Investimentos Externos Diretos, liderado, sobretudo, por conglomerados e empresas estatais, embora também com presença cada vez mais marcante de capital privado. Essas empresas operam no ambiente de concorrência oligopolista capitalista e, nesse sentido, podem ser analisadas usando as categorias desenvolvidas para estudar os fluxos de investimentos produtivos liderados pelas multinacionais ocidentais. Há, porém, algumas diferenças, principalmente a noção de fazer parte de estratégias de médio e longo prazo do próprio governo chinês. Nesse sentido, a atuação das estatais chinesas está associada a um processo de expansão apoiado pelo Estado no âmbito de uma luta geopolítica e geoeconômica visando maior influência e liderança, sobretudo na Ásia, na América Latina e na África. Entre os países alvos dessa estratégia se encontra o Brasil.

Neste ensaio, se focou na principal área de atuação das estatais chinesas no país, a da energia. Foi no ano 2010 que houve a entrada por meio de grandes aquisições das estatais Sinochem, Sinopec e State Gride. Analisou-se a diferença de atuação no segmento petrolífero, determinada pela busca de recursos para segurar o abastecimento do mercado chinês no qual o hiato entre a demanda e a produção interna continua em expansão. De outro lado, a atuação da State Gride no setor elétrico, que escolheu o Brasil como primeiro mercado não asiático para testar e consolidar sua liderança na tecnologia de transmissão e ultra-alta tensão (UHV). Seguindo a State Grid, outras duas gigantes estatais, a CTG e a SPIC também aproveitaram a oportunidade de ampliar rapidamente sua presença visando, sobretudo, ao controle de mercado na busca de uma liderança mundial. 
Em todos os casos analisados trata-se de empresas controladas e consideradas estratégicas pelo governo central e sua entrada no Brasil foi relativamente rápida por meio de aquisições de ativos e participações em licitações públicas. E, também, em ambos os setores, embora por motivos diferentes, a previsão é que estes investimentos se ampliem ainda mais. A importância de um entendimento dessas dinâmicas está na necessidade de o Brasil se preparar para aproveitar da melhor forma a presença delas em prol de seu desenvolvimento industrial-tecnológico. Qualquer debate sobre o desenvolvimento no Brasil deveria refletir sobre a internacionalização de setores tão estratégicos.

\section{REFERÊNCIAS}

ACIOLY, Luciana. China: uma inserção externa diferenciada. Economia Política Internacional - Análise estratégica. $\mathrm{N}^{\mathrm{o}}$ 7, Out/dezembro, 2005.

AEI - AMERICAN ENTERPRISE INSTITUTE; THE HERITAGE FOUNDATION. China Global Investment Tracker. Washington DC: American Enterprise Institute. Base de dados disponível em: <http://www.aei.org/China-global-investment-tracker/>. Acesso em: 30 de maio de 2017.

ANP - AGÊNCIA NACIONAL DO PETRÓLEO, GÁS NATURAL E BIOCOMBUSTÍVEL. Boletim Petróleo e P\&D. ed. 3. Rio de Janeiro, 2013.

Anuário Estatístico Brasileiro do Petróleo, Gás Natural e Biocombustíveis 2016. Rio de Janeiro: ANP, 2016.

ARRIGHI, Giovanni. Adam Smith em Pequim: origens e fundamentos do século XXI. São Paulo, Boitempo, 2008.

BERNING, Claire; HOLTBRUGGE, Dirk. STATE-OF-THE-ART Chinese outward foreign direct investment-a challenge for traditional internationalization theories? Journal Betriebswirtsch, Vol. 62, 2012.

BP - BRITISH PETROLEUM. Statistical Review of World Energy 2016. Base de dados disponível em: <http://www.bp.com/statisticalreview>. Acesso em: 20 jul 2017.

CARDOSO, Fernando Henrique; FALETTO, Enzo. Dependência e desenvolvimento na América Latina. Rio de Janeiro: Civilização Brasileira, 2004.

CINTRA, Marcos Antonio Macedo; FILHO, Edison Benedito da Silva; PINTO, Eduardo Costa (Organizadores). China em Transformação: dimensões econômicas e geopolíticas do desenvolvimento. Rio de Janeiro: Ipea, 2015.

CNOOC. Annual Report 2015. Bejing, 2015.

COMITÊ CENTRAL DO PARTIDO COMUNISTA DA CHINA. 13th Five Year Plan for Economic and Social Development of the People's Republic of China. Bejing, 2015.

Conselho Empresarial Brasil-China (CEBC). Investimentos chineses no Brasil 2016. São Paulo, 2017.

DUNNING, John Harry; LUNDAN, Sarianna. Theories of foreign direct investment. In:

DUNNING, John Harry; LUNDAN, Sarianna. Multinational Enterprises and the Global Economy. Cheltenham: Edward Elgar, 2008. 
EIA - U.S. ENERGY INFORMATION ADMINISTRATION. International Energy Outlook 2016. Washington, 2016.

ENERDATA INTELLIGENCE. Global Energy Estatistical Yearbook 2016. Grenoble, 2016.

FENBY, Jonathan. Tiger Head, Snake Tails: China today, how it got there and where it is heading. London: Simon\&Schuster, 2012.

FLASSBECK, Heiner. China's spectacular growth since the mid-1990: macroeconomic conditions and economic policy changes. In: United Nations. China in a globalizing world. New York/Geneva, 2005.

FUSER, Igor. Petróleo e Poder. O envolvimento militar dos Estados Unidos no Golfo Pérsico. São Paulo: Editora UNESP, 2008.

GILPIN, Robert. Global Political Economy. New Jersey: Princeton University Press, 2001.

HART-LANDSBERG, M;. BURKETT, P. China and the dynamics of international accumulation: causes and consequences of global restructuring. Historical Materialism, Vol. 14, nº 3, 2006.

IEA. INTERNATIONAL ENERGY AGENCY. Key Coal Trend Statistics. Paris, IEA, 2016.

LI, Qingnan; MA, Zheng; JØRGENSEN, Bo N. Discussion on China's Power Sector Reforms and Where to Next? Catalog $13^{\text {th }}$, International Conference on the European Energy Market. Porto, 2016.

NUNNENKAMP, Peter. Foreign direct investment in Latin America in the era of globalized production. Transnational Corporations. Vol. 6, $\mathrm{n}^{\circ}$ 1, abril 1997.

NYE, Joseph S. The Future of Power. ReadHowYouWant, 2011.

OECD. Science, Tecnology and Innovation Outlook 2016. Paris: OECD Publishing, 2016.

PANITCH, Leo; GINDIN, Sam. Rethinking production, finance and hegemonic decline in IPE. In: Pijl (Org) Handbook of the International Political Economy of Production. Cheltenham/ Northampton: Elgar Publishing, 2015.

House, 2012.

The Making of Global Capitalism. The political Economy of American Empire. Random

PAULSON INSTITUTE. Power Play: China's Ultra-High Voltage Technology and Global Standards. Lemont: Center for Energy, Environmental, and Economic Systems Analysis (CEEESA) - Argonne National Laboratory, 2015.

PIJL, Kees van der. Can China's Rise Continue Without Conflict? Paper presented at the Regional Perspectives for China and its Neighbours, conference, Confucius Institute, Leiden University, 5-6 January 2017.

The Making of an Atlantic Ruling Class. London/ Brooklyn: Verso, 2012.

QINGYUN, Li. As reformas econômicas da China. Palestra organizada pelo Conselho Empresarial BrasilChina (CEBC), em 14 de maio de 2014, na FAAP, em São Paulo. http://www.cebc.org.br/ptbr/evento/palestras-e-seminarios/palestra-professor-li-qingyun-reformas-economicas-da-china Acessado 14 de maio de 2017. 
SANTOS, Leandro; MILAN, Marcelo. Determinantes dos Investimentos Diretos Externos Chineses: aspectos econômicos e geopolíticos. Revista Contexto Internacional, Vol.36, n.2, 2014.

SCISSORS, Derek. Chinese Outword Investment: more opportunity than Danger. Backgrounder $\mathrm{n}^{\circ} 2579$. The Heritage Foundation, July 2011.

SCHUTTE, G. R.; DEBONE, V. S. . Trajetória e desafios da matriz energética chinesa. Economia e Políticas Públicas, v. 4, 2016.

SERVEN-SCHREIBER, Jean-Jacques. O Desafio Americano. São Paulo: Expressão Cultural, 1971.

SGBH - STATE GRID BRAZIL HOLDING. Demonstrações Financeiras 2016. Publicado no Valor Econômico, $24 / 03 / 2017$.

SGCC - STATE GRID CORPORATION OF CHINA. White Paper on Green Development. Shanghai: SGCC, 2010.

. CSR Report 2015. Shanghai: SGCC, 2015.

STRANGE, Susan (1998). States and Markets. New York: Ed. 2, Continuum. 2004.

UNCTAD. World Investment Report 2017. Investment and the Digital Economy. Genebra: United Nations, 2017.

WANG, Qiang; CHEN, Xi. China's electricity market-oriented reform: From an absolute to a relative monopoly. Energy Policy. Vol 51, dec. 2012.

WILLIAMSON, Peter; RAMAN, Anand. The Globe: how China reset its global acquisition agenda. Harvard Business Review, April, 2011.

WOO, Yuen Pau; ZHANG, Kenny . China Goes Global: The Implications of Chinese Outward Direct Investment for Canada. Canadian Economics Association. Annual Congress. Paper nº 892, 2006.

YERGIN, Daniel (2011). A Busca. Rio de Janeiro: Editora Intrínseca. Ed. digital: 2014.

Recebido em 06 de setembro de 2017. Aprovado em 19 de março de 2018. 


\title{
RESUMO
}

A partir do final da década de 2000, houve um fluxo de investimento expressivo de estatais chinesas do setor energético para o Brasil, em particular para os segmentos de petróleo e elétrico. Esses fluxos corresponderam a movimentos mais amplos, que transformaram a China de importador líquido em exportador líquido de capital. Este artigo analisa a dinâmica dessa presença no Brasil no contexto da busca por uma nova inserção internacional por parte do governo chinês e da atuação internacional das empresas envolvidas. Os investimentos no setor de petróleo refletem principalmente uma dinâmica anterior de resource-seeking que continua atual devido à alta dependência da matriz energética de fontes fósseis no geral e de importação de petróleo em específico. De outro lado, os investimentos das estatais do setor elétrico correspondem a uma estratégia de exportação de capitais e à conquista de mercados mais recentes, baseadas na liderança tecnológica.

Palavras-chave: China; IED; petróleo; setor elétrico; Brasil.

\begin{abstract}
Since the end of the 2000tees there has been a considerable amount of Chinese investments in Brazil's energy sector, specifically in oil and electricity. These flows are part of a wider movement that transformed China from a net recipient to a net exporter of capital. This article analyses the dynamics of this new reality in the Brazil case, in the framework of Chinese strategy for a new stage in its internationalization and the strategies of the companies involved. Investments in the oil sector correspond basically to a resourceseeking strategy that has been a reality for a longer period of time and reflects China's high dependence of fossil energy in general and import dependency of oil in specific. On the other hand, the investment flow in the electricity sector corresponds to a new strategy of capital export and market-seeking based on technological supremacy.
\end{abstract}

Key-words: China; FDI; petrol; electricity sector; Brazil. 